\title{
EFEKTIVITAS WEBSITE RUMAH SAKIT SEBAGAI MEDIA INFORMASI ERA PANDEMI
}

\author{
Intan Dwi Susanti, Wahyu Sulistiadi \\ Fakultas Kesehatan Masyarakat Universitas Indonesia \\ Email: intandsusanti94@gmail.com
}

\begin{abstract}
ABSTRAK
Pembatasan interaksi sosial masyarakat akibat pandemi COVID-19 yang terjadi secara global, meningkatkan penggunaan website di masyarakat. Website rumah sakit berkembang untuk menjadi salah satu media komunikasi antara rumah sakit dengan pasien dan calon pasien. Artikel ini berfokus pada analisis elemenelemen yang mempengaruhi efektivitas website rumah sakit pada pelayanan kesehatan. Penyusunan artikel dilakukan dengan mengidentifikasi website rumah sakit di beberapa negara. Elemen yang diharapkan terdapat pada website antara lain aksesibilitas, mobile friendly, konten informatif, transparansi pelayanan dan harga, keamanan data, dan mengakomodir komunikasi dua arah antara rumah sakit dan pasien atau calon pasien.
\end{abstract}

Kata Kunci: website, aksesibilitas, konten, informasi, pandemi COVID-19

\section{ABSTRACT}

Restrictions on public social interaction due to the global COVID-19 pandemic, increasing the use of website among people. The hospital website has developed to become one of the communication media between hospital and patients or forthcoming patients. This article focuses on analyzing the elements that influence the effectiveness of hospital website on health services. The article was compiled by identifying hospital websites in several countries. The elements that are expected to be found on the website include accessibility, mobile friendly, informative content, transparency of services and price, data security, and accommodating two-way communication between hospital and patients or forthcoming patients.

Keywords: website, accessibility, content, information, COVID-19 pandemic.

\section{PENDAHULUAN}

Penyebaran pandemi COVID-19 yang terjadi di seluruh dunia, diantisipasi oleh Pemerintah Indonesia dengan selalu menghimbau masyarakat untuk menerapkan protokol kesehatan 5M (memakai masker, mencuci tangan dengan sabun, menjaga jarak antar orang, menghindari kerumunan, serta mengurangi mobilitas). Himbauan pemerintah untuk menjaga jarak dan menghindari kerumunan ini menyebabkan adanya perubahan dalam pola interaksi sosial masyarakat. Perubahan interaksi sosial ini mempengaruhi cara komunikasi dan interaksi di rumah sakit. Perluasan interaksi dan komunikasi dilakukan dengan memanfaatkan wahana digital sebagai salah satu alternatif pilihan yang berfungsi untuk menjalankan pelayanan di rumah sakit.

http://ejournal.urindo.ac.id/index.php/MARSI
Penggunaan internet di Indonesia pada periode 2019 hingga kuartal II tahun 2020, tercatat sebanyak 196,71 juta atau setara dengan $73,7 \%$ populasi di Indonesia [1]. Banyaknya pengguna internet aktif di Indonesia menjadikan website sebagai platform penting yang digunakan tidak hanya bagi media digital, tetapi juga digunakan pada pelayanan publik di berbagai sektor. Rumah sakit juga termasuk ke dalam sektor pelayanan yang mulai menggunakan website sebagai bagian dari piranti pelayanannya. Pelayanan rumah sakit yang merambah bidang digital terutama website meliputi pelayanan informasi kesehatan, pendaftaran daring, dan konsultasi kesehatan secara daring [2].

Informasi yang ditampilkan rumah sakit pada website-nya diharapkan dapat membantu pasien dan calon pasien dalam mendapatkan informasi 
kesehatan, pilihan terapi, pilihan dokter, dan fasilitas rumah sakit [3]. Dengan luasnya jangkauan akses pada website, maka website rumah sakit juga diharapkan bisa meningkatkan pelayanan, menjadi penambah jumlah okupansi rumah sakit dan pendukung program kesehatan pemerintah dalam program kesehatan masyarakat [4]. Artikel ini bertujuan untuk mengetahui apa saja elemen yang mempengaruhi efektivitas website rumah sakit pada pelayanan kesehatan.

\section{METODE}

\section{Kriteria Inklusi:}

Ditentukan dengan melihat rumah sakit dari beberapa negara yang dilengkapi dengan fasilitas website. Intervensi yang menjadi perhatian adalah pemanfaatan website rumah sakit di masa pandemi COVID-19 ini. Hasil yang ingin diketahui adalah elemen apa saja yang mempengaruhi efektivitas website rumah sakit pada pelayanan kesehatan. Artikel yang ditelusuri merupakan artikel berbahasa Inggris dengan tahun publikasi artikel dari 2019 hingga Mei 2021. Artikel juga berbentuk full-text dengan lingkup penelitian. Bagi artikel yang memenuhi syarat tersebut, namun terdapat keterbatasan akses, maka tidak dimasukkan dalam penyusunan artikel ini.

\section{Sumber Data:}

Penelusuran artikel dilakukan pada databases seperti ProQuest, PubMed dan Google Scholar.
Kata kunci yang digunakan untuk menelusuri artikel, yaitu website AND accessibility AND content AND information AND COVID-19 pandemic.

\section{Pengumpulan Data dan Analisis:}

Setelah penulis mengidentifikasi artikel melalui databases, seluruh artikel diimpor ke perangkat lunak Mendeley. Artikel diseleksi berdasarkan judul, abstrak, dan bentuk artikel full-text. Kemudian duplikasi artikel yang teridentifikasi dikeluarkan dari Mendeley. Proses selanjutnya adalah mengekstrak data penulis pertama, judul dan negara studi, serta elemen yang mempengaruhi efektivitas website rumah sakit. Setelah itu, proses input data dalam bentuk tabel dengan Microsoft Word 2019.

Pada tahap skrining awal, 925 artikel teridentifikasi dari databases dengan rincian penemuan 913 artikel di ProQuest, 8 artikel di PubMed, dan 4 artikel di Google Scholar. Berdasarkan jumlah tersebut, 14 artikel duplikat dieliminasi. Penulis mengevaluasi judul dan abstrak dari 911 artikel, kemudian 901 artikel dieliminasi dan 10 artikel dimasukkan dalam analisis full-text. Selanjutnya, ada 3 artikel yang dikecualikan karena tidak berkaitan dengan pertanyaan artikel ini sehingga ada 7 artikel penelitian yang digunakan sebagai referensi untuk menjawab tujuan artikel ini. Proses penyusunan artikel ini digambarkan dalam Gambar 1.

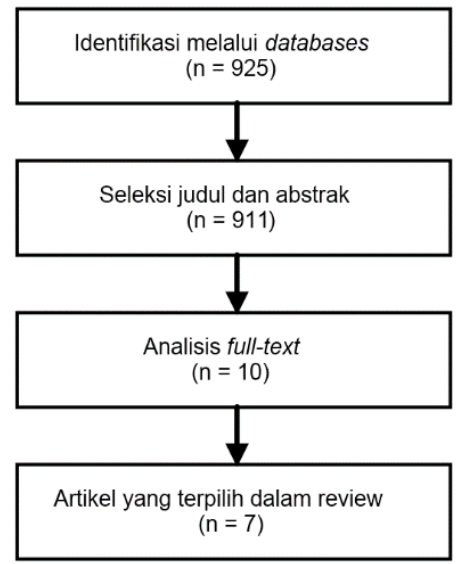

Gambar 1. Ringkasan proses identifikasi artikel 


\section{HASIL DAN PEMBAHASAN}

Saat ini, dengan perkembangan internet yang pesat, pencarian informasi menjadi lebih mudah. Penggunaan website sebagai sarana komunikasi rumah sakit dengan pasien dan calon pasien akan melengkapi tersedianya layanan pasien yang cepat, responsif, dan terpercaya [5]. Website rumah sakit dirancang untuk memenuhi elemenelemen pelayanan yang dibutuhkan oleh pasien dan calon pasien. Penentuan dan evaluasi kualitas elemen-elemen website rumah sakit bersifat dinamis karena teknologi dan informasi yang juga berkembang dengan pesat [6]. Rangkuman hasil pencarian artikel disajikan pada Tabel 1.

Tabel 1. Ringkasan hasil review

\begin{tabular}{|c|c|c|}
\hline Penulis & Judul (Negara) & Hasil \\
\hline $\begin{array}{l}\text { Król \& } \\
\text { Zdonek, } \\
2021[7]\end{array}$ & $\begin{array}{l}\text { The Quality of Infectious } \\
\text { Disease Hospital Websites in } \\
\text { Poland in Light of the COVID-19 } \\
\text { Pandemic (Polandia) }\end{array}$ & $\begin{array}{l}\text { Elemen performa, SEO, aksesibilitas, dan mobile } \\
\text { friendliness mempengaruhi efektivitas website } \\
\text { rumah sakit. }\end{array}$ \\
\hline $\begin{array}{l}\text { Tejedor } \\
\text { et al., } \\
2020[8]\end{array}$ & $\begin{array}{l}\text { Tracking Websites' Digital } \\
\text { Communication Strategies in } \\
\text { Latin American Hospitals } \\
\text { During the COVID-19 Pandemic } \\
\text { (Amerika Latin) }\end{array}$ & $\begin{array}{l}\text { Elemen kemudahan bagi user, hubungan interaktif } \\
\text { dengan user, jenis informasi yang ditawarkan, } \\
\text { social media dan konten yang update, referensi } \\
\text { terpercaya, serta aksesibilitas mempengaruhi } \\
\text { efektivitas website rumah sakit. }\end{array}$ \\
\hline $\begin{array}{l}\text { Jiao et } \\
\text { al., } 2020 \\
{[2]}\end{array}$ & $\begin{array}{l}\text { Factors Influencing Information } \\
\text { Service Quality of China } \\
\text { Hospital: The Case Study of } \\
\text { since } 2017 \text { of a Hospital } \\
\text { Information Platform in China } \\
\text { (Cina) }\end{array}$ & $\begin{array}{l}\text { Elemen pelayanan medis online, informasi } \\
\text { pelayanan medis online, informasi interaktif online, } \\
\text { pelayanan digital media, pelayanan informasi } \\
\text { dengan resource berkualitas, pelayanan informasi } \\
\text { dengan resource administrasi, pelayanan informasi } \\
\text { berteknologi, serta desain informasi } \\
\text { mempengaruhi efektivitas website rumah sakit. }\end{array}$ \\
\hline $\begin{array}{l}\text { Meyer, } \\
2020[9]\end{array}$ & $\begin{array}{l}\text { COVID-19 Pandemic } \\
\text { Accelerates Need to Improve } \\
\text { Online Patient Engagement } \\
\text { Practices to Enhance Patient } \\
\text { Experience (Amerika) }\end{array}$ & $\begin{array}{l}\text { Elemen harga pelayanan, estimasi biaya, metode } \\
\text { pembayaran, akses rekam medis, penjadwalan } \\
\text { pertemuan, dan akses pelayanan telehealth } \\
\text { mempengaruhi efektivitas website rumah sakit. }\end{array}$ \\
\hline $\begin{array}{l}\text { Koyama } \\
\text { et al., } \\
2019[10]\end{array}$ & $\begin{array}{l}\text { How does a Hospital Website } \\
\text { Branding have Positive Effects } \\
\text { of Patients Visiting and } \\
\text { Hospital Recruitment? (Jepang) }\end{array}$ & $\begin{array}{l}\text { Elemen pembaruan konten secara berkala } \\
\text { mempengaruhi efektivitas website rumah sakit. }\end{array}$ \\
\hline $\begin{array}{l}\text { Bach et } \\
\text { al., } 2019 \\
{[11]}\end{array}$ & $\begin{array}{l}\text { Hospital Websites: From the } \\
\text { Information Repository to } \\
\text { Interactive Channel (Bosnia } \\
\text { dan Herzegovina, Kroasia, } \\
\text { Slovenia) }\end{array}$ & $\begin{array}{l}\text { Elemen teknis, informasi rumah sakit dan } \\
\text { fasilitasnya, admisi dan pelayanan medis, } \\
\text { pelayanan online interaktif, dan aktivitas eksternal } \\
\text { mempengaruhi efektivitas website rumah sakit. }\end{array}$ \\
\hline $\begin{array}{l}\text { Perçin, } \\
2019[5]\end{array}$ & $\begin{array}{l}\text { A Combined Fuzzy Multicriteria } \\
\text { Decision-Making Approach for } \\
\text { Evaluating Hospital Website } \\
\text { Quality (Turki) }\end{array}$ & $\begin{array}{l}\text { Elemen pelayanan pelanggan, responsivitas, } \\
\text { pelayanan teknis, keandalan, konten visual, dan } \\
\text { keamanan mempengaruhi efektivitas website } \\
\text { rumah sakit. }\end{array}$ \\
\hline
\end{tabular}


Elemen-elemen kualitas website menjadi dasar untuk merancang strategi pengembangan rumah sakit $[12,13]$. Beberapa elemen kualitas antara lain aksesibilitas, mobile friendliness, konten website, transparansi pelayanan dan harga, serta keamanan website. Website harus dapat diakses terus menerus sehingga pelayanan tidak terpengaruh dan perkembangan bisa dipantau secara real time $[7,8,14]$. Akses website melalui perangkat smartphone sudah menjadi hal umum. Pengembangan website rumah sakit juga diharapkan sudah mengadopsi mobile friendliness agar experience pengakses akan sama seperti yang didapatkan ketika mengakses website melalui peramban pada komputer pribadi [7]. Konten dari website diharapkan juga selalu diperbaharui dengan informasi-informasi kesehatan terbaru dan juga membantu pemerintah di era pandemi COVID-19 dengan menghadirkan informasi yang benar dan tervalidasi [15-17]. Pelayanan rumah sakit yang ditampilkan dalam website rumah sakit, sebaiknya juga disertai dengan harga pelayanannya agar informasi semakin jelas bagi pasien dan calon pasien [2,9]. Elemen terakhir yang melindungi semua pelayanan pada website rumah sakit adalah keamanan website itu sendiri. Website rumah sakit haruslah aman dan terenkripsi agar tidak terjadi kasus pencurian data ataupun peretasan website yang berdampak pada pelayanan dan privasi rumah sakit dan pasien [5].

Penggunaan website oleh rumah sakit masih terbatas pada komunikasi satu arah. Website rumah sakit secara umum berisi informasi umum, fasilitas yang ada, serta jadwal dokter $[14,18]$. Dalam hal meningkatkan pelayanannya, rumah sakit diharapkan mengembangkan platform komunikasi dua arah dalam website-nya. Komunikasi dua arah pada website rumah sakit, bisa berupa pendaftaran dan layanan interaktif pasien. Pengembangan komunikasi dua arah pada website rumah sakit, selain untuk mempermudah pasien dan calon pasien, juga sebagai sarana dalam meminimalisir kontak langsung serta bisa dikembangkan menjadi bentuk skrining awal kepada pasien dan calon pasien di era pandemi COVID-19 ini $[2,11]$.

Media website rumah sakit diharapkan menjadi gambaran kelaikan pelayanan teknis, kualitas, serta menjadi solusi inovatif yang merepresentasikan pelayanan rumah sakit serta berpengaruh pada persepsi pasien dan calon pasien dalam pemilihan rumah sakit $[5,19]$. Penambahan layanan website rumah sakit diharapkan bisa menjadi peningkatan daya dukung bisnis rumah sakit [11]. Pembentukan divisi khusus yang membawahi pelayanan melalui website diharapkan bisa fokus untuk melayani komunikasi website baik satu arah maupun dua arah kepada pasien dan calon pasien.

\section{KESIMPULAN}

Website sebagai media komunikasi yang dapat diakses secara masif diharapkan memiliki elemen aksesibilitas yang baik, mobile friendly, konten website yang baik dan informatif, transparansi pelayanan dan harga, keamanan data yang baik, serta mengakomodir komunikasi dua arah antara rumah sakit dan pasien atau calon pasien. Pada era pandemi COVID-19 ini, website rumah sakit juga diharapkan menjadi penyedia informasi yang benar dan tervalidasi untuk menunjang kesehatan masyarakat.

\section{DAFTAR PUSTAKA}

[1] APJII. Buletin APJII Edisi 85 April 2021. Asosiasi Penyelenggara Jasa Internet Indonesia [Internet]. 2021;1-10. Available from: https://www.apjii.or.id/content/read/104/ 531/BULETIN-APJII-EDISI-85---April-2021

(Diakses 08 Juni 2021).

[2] Jiao L, Xiao $H$, Zhu X, Zhao X. Factors Influencing Information Service Quality of China Hospital: The Case Study of since 2017 of a Hospital Information Platform in China. Comput Math Methods Med. 2020;2020:1-17.

[3] Chi E, Jabbour N, Aaronson NL. Quality and Readability of Websites for Patient Information on Tonsillectomy and Sleep Apnea. Int J Pediatr Otorhinolaryngol. 2017;98:1-3.

[4] Fiksdal AS, Kumbamu A, Jadhav AS, Cocos $C$, Nelsen LA, Pathak J, et al. Evaluating the Process of Online Health Information Searching: A Qualitative Approach to Exploring Consumer Perspectives. J Med 
Internet Res. 2014;16(10):1-9.

[5] Perçin S. A Combined Fuzzy Multicriteria Decision-Making Approach for Evaluating Hospital Website Quality. J Multi-Criteria Decis Anal. 2019;26:129-44.

[6] Benito-Osorio D, Peris-Ortiz $M$, Armengot $\mathrm{CR}$, Colino A. Web 5.0: The Future of Emotional Competences in Higher Education. Glob Bus Perspect. 2013;1:27487.

[7] Król K, Zdonek D. The Quality of Infectious Disease Hospital Websites in Poland in Light of the COVID-19 Pandemic. Int J Environ Res Public Health. 2021;18:2-19.

[8] Tejedor S, Pérez-Escoda A, Ventín A, Tusa F, Martínez F. Tracking Websites' Digital Communication Strategies in Latin American Hospitals During the COVID-19 Pandemic. Int J Environ Res Public Health. 2020;17:1-19.

[9] Meyer MA. COVID-19 Pandemic Accelerates Need to Improve Online Patient Engagement Practices to Enhance Patient Experience. J Patient Exp. 2020;7(5):657-64.

[10] Koyama T, Takahashi K, Takahashi A, Takeda Y. How does a Hospital Website Branding have Positive Effects of Patients Visiting and Hospital Recruitment? J Hosp Manag Heal Policy. 2019;3(20):1-8.

[11] Bach MP, Seljan S, Jaković B, Buljan A, Zoroja J. Hospital Websites: From the Information Repository to Interactive Channel. Procedia Comput Sci. 2019;164:64-71.
[12] Liang CJ, Chen HJ. A Study of the Impacts of Website Quality on Customer Relationship Performance. Total Qual Manag Bus Excell. 2009;20(9):971-88.

[13] Sun CC, Lin GTR. Using Fuzzy TOPSIS Method for Evaluating the Competitive Advantages of Shopping Websites. Expert Syst Appl. 2009;36:11764-71.

[14] Bedell SE, Agrawal A, Petersen LE. A Systematic Critique of Diabetes on the World Wide Web for Patients and Their Physicians. Int J Med Inform. 2004;73:68794.

[15] Gong K, Xu Z, Cai Z, Chen Y, Wang Z. Internet Hospitals Help Prevent and Control the Epidemic of COVID-19 in China: Multicenter User Profiling Study. J Med Internet Res. 2020;22(4):1-9.

[16] Hantrais L, Allin P, Kritikos $M$, Sogomonjan $\mathrm{M}$, Anand PB, Livingstone S, et al. Covid-19 and the Digital Revolution. Contemp Soc Sci. 2021;16(2):256-70.

[17] Allington D, Duffy B, Wessely S, Dhavan N, Rubin J. Health-Protective Behaviour, Social Media Usage, and Conspiracy Belief During the COVID-19 Public Health Emergency. Psychol Med. 2020;1-7.

[18] Bilsel RU, Büyüközkan G, Ruan D. A Fuzzy Preference-Ranking Model for a Quality Evaluation of Hospital Web Sites. Int J Intell Syst. 2006;21:1181-97.

[19] Aladwani AM, Palvia PC. Developing and Validating an Instrument for Measuring User-Perceived Web Quality. Inf Manag. 2002;39:467-76. 